\section{Bosentan-Induced Drug Reaction with Eosinophilia and Systemic Symptoms (DRESS) Syndrome}

\section{To the Editor:}

Bosentan is an orally administered dual endothelin-1 receptor antagonist approved for use in patients with pulmonary arterial hypertension and for reducing the number of new digital ulcers in patients with systemic sclerosis $(\mathrm{SSc})$. Adverse events associated with bosentan are mainly teratogenicity and hepatotoxicity. We describe a patient with SSc who had previous skin allergy occurrence following the use of various drugs, and who developed a severe hypersensitive reaction after bosentan administration. Bosentan contains a $-\mathrm{SO}_{2} \mathrm{NH}_{2}$ moiety and belongs to the sulfonamide nonantibiotic drugs that might have contributed to this adverse event.

A 71-year-old woman weighing $63 \mathrm{~kg}$ was diagnosed with SSc 16 years before and was classified as having diffuse cutaneous disease with positive antitopoisomerase I antibodies. Her disease had led to pulmonary fibrosis but without significant restrictive syndrome and also to recurrent digital ulcerations. Her longterm stable treatment included nicardipine, domperidone, omeprazole, coumadine, prednisone ( $8 \mathrm{mg} /$ day), zolpidem, and hydroxyzine. She was known for having developed hypersensitive skin reactions following aspirin, penicillin, and cotrimoxazole use. She had new digital ulcerations in June 2009 and she received intravenous iloprost over 5 days. Because of recurrent digital ulcers, bosentan $(62.5 \mathrm{mg}$, bid $)$ was started on August 1, 2009, in addition to her stable treatment. The bosentan dose was increased to $125 \mathrm{mg}$ twice a day at the beginning of September while liver enzyme remained within normal range. On September 16 she experienced fever $\left(38^{\circ} \mathrm{C}\right)$, generalized maculopapular exanthema, and headache. Blood tests September 22 revealed hepatitis with 20-fold increased alanine aminotransferase (ALT) values and a marked increase in eosinophil count $(2500 / \mathrm{ml})$. Bosentan was stopped the same day. For personal reasons, she delayed her visit to the inpatient clinic until September 30 but had some other blood tests. Clinically, she improved within 4 days and, at the time of her visit, she felt better, skin reaction had disappeared, and echography ruled out any biliary problems. The blood tests revealed an improvement in ALT values and normalization of the eosinophil count. Hepatitis virus serologies were negative and herpes virus simplex type 6 polymerase chain reaction in sera was also negative. We assume that this case relates to a DRESS syndrome (drug rash with eosinophilia and systemic symptoms), also called drug-induced hypersensitivity syndrome. Indeed, this case, associating generalized rash, fever, and liver cytolysis, fulfills the criteria proposed by the new RegiSCAR group ${ }^{1}$. The clinical manifestations typically occur within 2-6 weeks after starting the therapy and improve in most cases when the drug is discontinued, without sequelae. However, death was reported in $10 \%$ of such cases. The outcome is determined by the occurrence of visceral complications such as fulminant hepatitis, interstitial nephropathy, eosinophilic interstitial pneumopathy, pericarditis, myocarditis, or pancreatitis ${ }^{2-4}$. A study of the European postmarketing surveillance of bosentan reported a $7.6 \%$ incidence of hepatitis (annual rate of $10.1 \%$ ). Fewer other side effects outside clinical worsening or hepatitis were reported but with a frequency of $6.2 \%$ of "other adverse effects" and $1.3 \%$ of effects not included in the summary of product characteristics ${ }^{5}$. The literature provides 2 other cases of probable DRESS syndrome brought on by bosentan ${ }^{6,7}$. Taking into account the history of our patient, with several adverse reactions to other drugs, we looked at the chemical structure of bosentan, which revealed a sulfonamide moiety (Figure 1). It also appeared that, among other endothelin antagonists, sitaxentan also contains a sulfonamide moiety (Figure 1). Looking at the summary of bosentan characteristics ${ }^{8}$, we found that according to the different trials, erythema may be frequent and that hypersensitivity reactions including dermatitis, pruritus, and rash are uncommon; however, the sulfonamide functional group is not stated. Although some authors suggest avoiding any sulfonamides following a history of sulfa allergy, cross-reactivity between sulfonamide antibiotics and sulfamide nonantibiotics remains a matter of debate and some arguments support the concept of overall predisposition to allergic drug reactions for some individuals rather than direct cross-reactivity 9,10 .

This is the third case of hypersensitivity related to bosentan. Because DRESS is potentially life-threatening, we suggest that all practitioners be aware of this risk. They should try to avoid as much as possible severe adverse hypersensitivity reactions by carefully checking the patient's allergic history before prescription.

YANNICK ALLANORE, MD, PhD, Professor of Rheumatology, INSERM U781, Necker Hospital; LAURENCE MOACHON, MD,

Pharmacovigilance Department, Paris Descartes University, Cochin Hospital, EMILIE MAURY, MD; ANNE ISVY, Fellow; ANDRÉ

KAHAN, MD, PhD, Professor of Rheumatology, Paris Descartes University, Cochin Hospital, Rheumatology A; Paris, France. Address correspondence to Dr. Allanore; E-mail: yannick.allanore@cch.aphp.fr
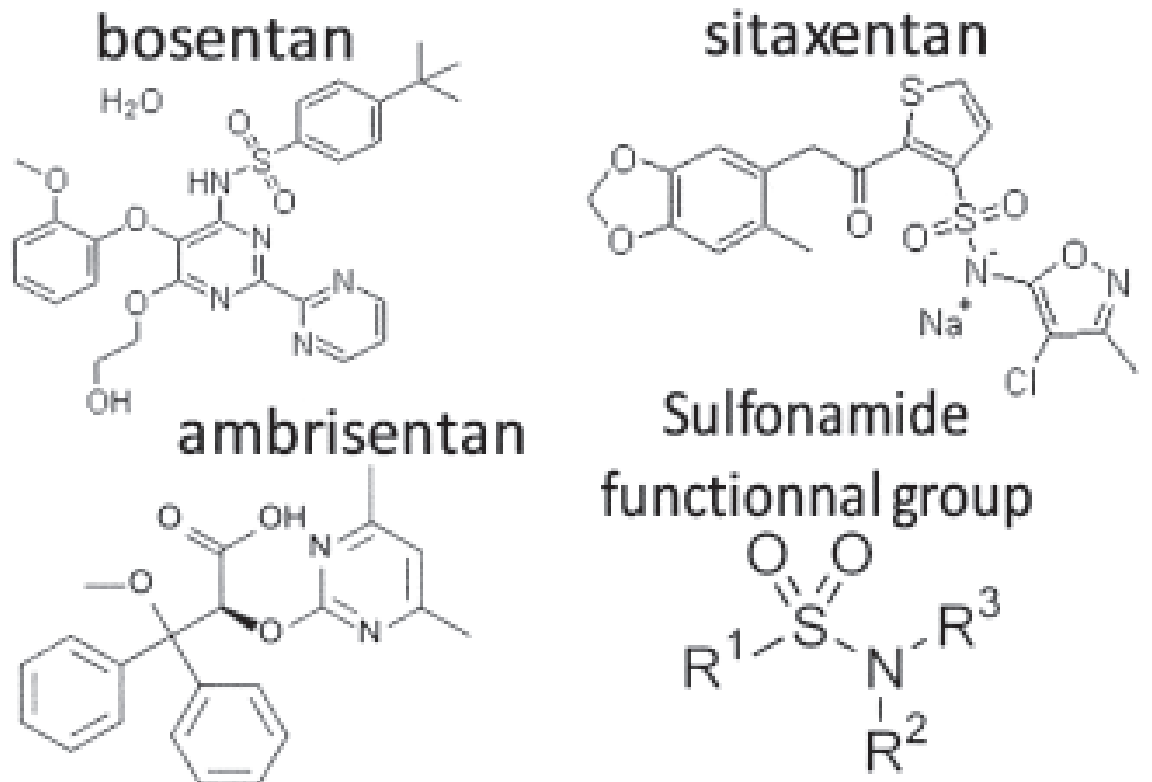

Figure 1. Chemical structures of endothelin antagonists and of sulfonamide. 


\section{REFERENCES}

1. Kardaun SH, Sidoroff A, Valeyrie-Allanore L, Halevy S, Davidovici BB, Mockenhaupt M, et al. Variability in the clinical pattern of cutaneous side-effects of drugs with systemic symptoms: does a DRESS syndrome really exist? Br J Dermatol 2007;156:609-11.

2. Mardivirin L, Valeyrie-Allanore L, Branlant-Redon E, Beneton N, Jidar K, Barbaud A, et al. Amoxicillin-induced flare in patients with DRESS (Drug Reaction with Eosinophilia and Systemic Symptoms): report of seven cases and demonstration of a direct effect of amoxicillin on human herpesvirus 6 replication in vitro. Eur J Dermatol 2010;20:68-73.

3. Ben m'rad M, Leclerc-Mercier S, Blanche P, Franck N, Rozenberg F, Fulla Y, et al. Drug-induced hypersensitivity syndrome: clinical and biologic disease patterns in 24 patients. Medicine 2009;88:131-40

4. Eshki M, Allanore L, Musette P, Milpied B, Grange A, Guillaume $\mathrm{JC}$, et al. Twelve-year analysis of severe cases of drug reaction with eosinophilia and systemic symptoms: a cause of unpredictable multiorgan failure. Arch Dermatol 2009;145:67-72.
5. Humbert M, Segal ES, Kiely DG, Carlsen J, Schwierin B, Hoeper MM. Results of European postmarketing surveillance of bosentan in pulmonary hypertension. Eur Respir J 2007;30:338-44.

6. Nagai Y, Yamanaka M, Nishimura S, Nakano A, Hasegawa A, Ishikawa O. Drug eruption due to bosentan in a patient with systemic sclerosis. Mod Rheumatol 2006;16:188-90.

7. Romano A, Giovannetti A, Caruso C, Rosato E, Pierdominici M, Salsano F. Delayed hypersensitivity to bosentan. Allergy 2009;64:499-501.

8. Actelion Ltd. Summary of bosentan product characteristics. January 2010. [Internet. Accessed February 11, 2010.] Available from: http://www1.actelion.com/documents/corporate/smpc_pils/ Tracleer_SmPC.pdf

9. Strom BL, Schinnar R, Apter AJ, Margolis DJ, Lautenbach E, Hennessy S, et al. Absence of cross-reactivity between sulfonamide antibiotics and sulfonamide nonantibiotics. N Engl J Med 2003;349:1628-35.

10. Brackett CC. Sulfonamide allergy and cross-reactivity. Curr Allergy Asthma Rep 2007;7:41-8.

J Rheumatol 2010;37:5; doi:10.3899/jrheum.091266 